\title{
A new high-pressure recycle-flow calorimeter and results of determinations with ethane
}

\author{
T. MIYAZAKI, ${ }^{a}$ A. V. HEJMADI, and J. E. POWERS \\ Department of Chemical Engineering, \\ The University of Michigan, \\ Ann Arbor, Michigan 48109, U.S.A.
}

(Received 22 February 1977; in revised form 26 February 1979)

\begin{abstract}
A new recycle-flow calorimeter is described with which the thermodynamic properties of fluids can be determined between pressures of 2 to $20 \mathrm{MPa}$ and temperatures of 90 to $400 \mathrm{~K}$. Precise control of both flowrate and pressure is provided by dual precision metering pumps. Details are presented on a new calorimeter which incorporates several innovations. Heat losses from this calorimeter are reduced by a novel shielding arrangement and were shown to be less than the experimental precision of \pm 0.1 per cent. The calorimeter can be operated in either the isobaric or the throttling mode. The results of experimental determinations around the critical point of ethane are described. Enthalpies of vaporization and heat capacities were obtained by operating in the isobaric mode. Determinations in the throttling mode yielded isothermal throttling coefficients and Joule-Thomson coefficients. Analysis of these results showed that the thermodynamic consistency of the enthalpies in the isobaric and isothermal mode is better than 0.1 per cent, and that of the derived values of properties is 0.4 per cent or hetter.
\end{abstract}

\section{Introduction}

Accurate values of the physical properties of fluids are essential for designing energyefficient process equipment. Of "particular importance are the thermodynamic properties: enthalpy, heat capacity, and the throttling coefficients. In recognition of this need, extensive direct calorimetric determinations of the effect of pressure and temperature on the enthalpy of pure compounds and mixtures over a wide range of conditions have been carried out at the Thermal Properties of Fluids Laboratory, as reviewed in detail elsewhere. ${ }^{(1)}$ These results were obtained on a recycle flow facility which had been developed over the past 20 years.

By building on this past experience and incorporating new ideas, it was reasoned that an entirely new recycle-flow facility might be built which would not only yield results of improved accuracy but which would also prove to be considerably easier to control and operate. The purposes of this paper are to describe such a facility and to present calorimetric results obtained whth ethane near its critical point.

Details of the bases of flow calorimetry and the interpretation of results obtained on such facilities have been presented elsewhere. ${ }^{(2)}$ In brief, fluid of constant

a Presently with Asahi Chemical Industry Co., Tokyo, Japan. 
composition $x$ flows through a calorimeter under steady-state conditions. When the calorimeter is properly designed and operated, both kinetic and potential effects are negligible and the calorimeter is, to all intents and purposes, adiabatic. Measured quantities of electric power $P$ may be transferred to the fluid in the calorimeter during the course of the experiment. Under these constraints, the first law of thermodynamics reduces to

$$
h\left(T_{0}, p_{\mathrm{o}}\right)-h\left(T_{\mathrm{i}}, p_{\mathrm{i}}\right)=-P / F,
$$

where the subscripts $o$ and i serve to identify the state (temperature and pressure) at the outlet and inlet of the flow calorimeter and $F$ denotes the mass flow rate.

In isobaric determinations, $p_{\mathrm{o}} \approx p_{\mathrm{i}}$, and electric power serves to increase the temperature-or to bring about a phase change. In the throttling mode, $p_{\mathrm{o}} \ll p_{\mathrm{i}}$, in which case: $P=0$ for Joule-Thomson experiments, or $t_{\mathrm{o}} \approx t_{\mathrm{i}}$ for isothermal (Eucken) determinations.

\section{Equipment}

The new apparatus was designed to improve upon the performance of the old in key ways : by yielding results of higher precision, by easier operation and over a wider range of conditions, and by requiring less working fluid. These objectives were attained by complementary achievements in two principal areas: the development of a single calorimeter capable of accurate results in both the isobaric and throttling modes; and the employment of superior methods for control and measurement of flow and of pressure of the working fluid. These two capabilities were integrated into a suitably designed well instrumented apparatus. A description of the most important features of all of these items follows, with details presented elsewhere. ${ }^{(3)}$

\section{CALORIMETER}

The key criteria selected in designing the new calorimeter were (a) to incorporate capability for isobaric and throttling determinations in a single calorimeter (both operation and instrumentation are simpler with one rather than two or more calorimeters); (b) to eliminate pressure seals at calorimeter operating temperatures, so that no pressure leaks will result from thermal expansion effects caused by varying calorimeter-bath temperatures; (c) to reduce heat losses to negligible values even at low flow rates; (d) to reduce the time to reach steady-state by reducing the mass of the calorimeter ; (e) to achieve a basic design which will permit operation at pressures up to $100 \mathrm{MPa}$ over a wide range of temperatures. The following description of the calorimeter illustrates briefly how each of these key criteria were satisfied.

FIGURE 1. Schematic diagram illustrating the technique used in incorporating both isobaric and throttling capabilities in a single calorimeter. $1,4.76 \mathrm{~mm}$ o.d. tubing; $2,0.07 \mathrm{~cm}$ i.d. capillary tubing; 3 , electric heating wire; $4,3.18 \mathrm{~mm}$ o.d. tubing; 5 , shut-off valve; 6 , plunger; 7 , spring; $8,1.58 \mathrm{~mm} 0 . \mathrm{d}$. tubing; $9,0.5 \mathrm{~mm}$ piano wire; 10 , turning handle; 11 , wire adjuster ; 12 , stem ; 13 , spring; 14 , electric heater lead; $15,3.18 \mathrm{~mm}$ o.d. tubing; 16 , electric-potential measurements tap; $17,4.76 \mathrm{~mm}$ o.d. tubing; 18 , lead wire seal unit ; 19 , wire seal fitting; 20 , pressure tap; $\mathbf{A}$, heating zone; $\mathbf{B}$, mixing zone. 


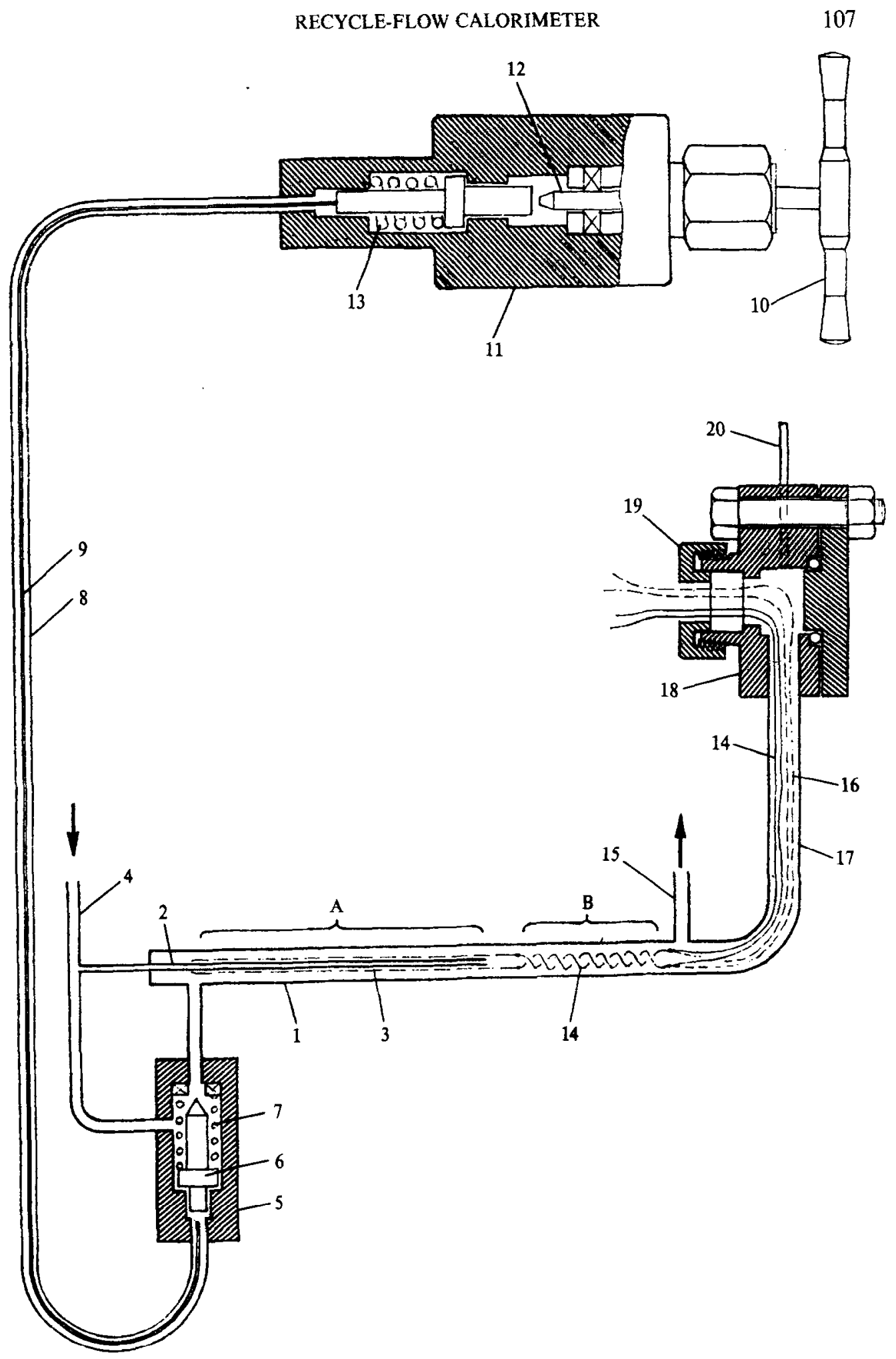


The technique used in incorporating both isobaric and throttling in a single calorimeter is illustrated schematically in figure 1 . This is achíeved using concentric tubes 1 and 2 in the heating section $A$, together with a small externally-activated selfsealing shut-off valve 5 . The outer tube 1 is $4.75 \mathrm{~mm}$ o.d. The capillary inner tube 2 $(0.07 \mathrm{~cm}$ i.d.) is wrapped with heating wire 3 . When the valve 5 is open (as shown), fluid flows through both tubes 1 and 2 and the pressure drop is low $(\approx 0.0005 \mathrm{MPa})$ yielding effectively isobaric determinations. With the valve closed, the entire flow is forced through the capillary, resulting in a high pressure drop, thus yielding throttling (isothermal or isenthalpic) results. The valve is remotely activated by a valve handle assembly 11 through a piano wire 9 .

After exiting from the heating section A the fluid is mixed in section B by flowing over twisted and stuffed heater lead wires 14 and then exits through tubing 15 . The heater lead wires 16 are led out of a Conax gland 19 in gland assembly 18 . The pressure at the calorimeter outlet is measured through tap 20.

As may be seen in figure 1, there are only two high-pressure seals in this entire unit: one on the valve handle assembly 11 and the other in the Conax gland 19. Both of these are outside the calorimeter and are maintained at ambient conditions as desired.

The actual configuration of the arrangement (illustrated schematically by figure 1) and its incorporation into the calorimeter itself is shown in figure 2. The inlet fluid passes the inlet-pressure tap junction $P$ and inlet-thermometer well $T 1$, before flushing the two concentric radiation shields $R 1$ and $R 2$. It then enters a $T$ and valve 5 which directs the fluid through one or both of the concentric tubes in the heating section 6 as was illustrated in figure 1. After thorough mixing in the tubes downstream from the heating section, the fluid passes through a tube surrounding the outlet-thermometer well T2, and exits from the calorimeter through a coiled tube which was designed to reduce conductive heat transfer with the bath. The lead wires from the heater in 6 are led out through the calorimeter outlet-pressure tap 4 to a Conax gland (19 in figure 1).

Heat losses are reduced in several ways. Shields R1, R2, R3, and R4 reduce radiative heat transfer with the surroundings. The calorimeter assembly is insulated by a vacuum jacket 1 . Finally, the lengths and diameters of all the tubing leading in and out of the calorimeter are designed to reduce conduction losses.

The calorimeter is constructed entirely from $3.18 \mathrm{~mm}$ and $4.76 \mathrm{~mm}$ tubing, which helps to satisfy the remaining criteria. Using welded tubing throughout rather than having high-pressure closure devices reduces the mass and hence improves the response time to changes in calorimeter conditions. A further advantage of small o.d. tubing is that the same basic design can be scaled up to high pressures by slight changes in wall thickness. Thus, though the present calorimeter is capable of operating only up to $20 \mathrm{MPa}$, the basic design can be used up to $100 \mathrm{MPa}$.

\section{FLOW METERING}

The wide range of operation and the exceptionally precise results obtainable on the present dual-purpose calorimeter are due primarily to the special precision-machined piston pumps, designed by the late Walter Ruska of Rice University. These two 


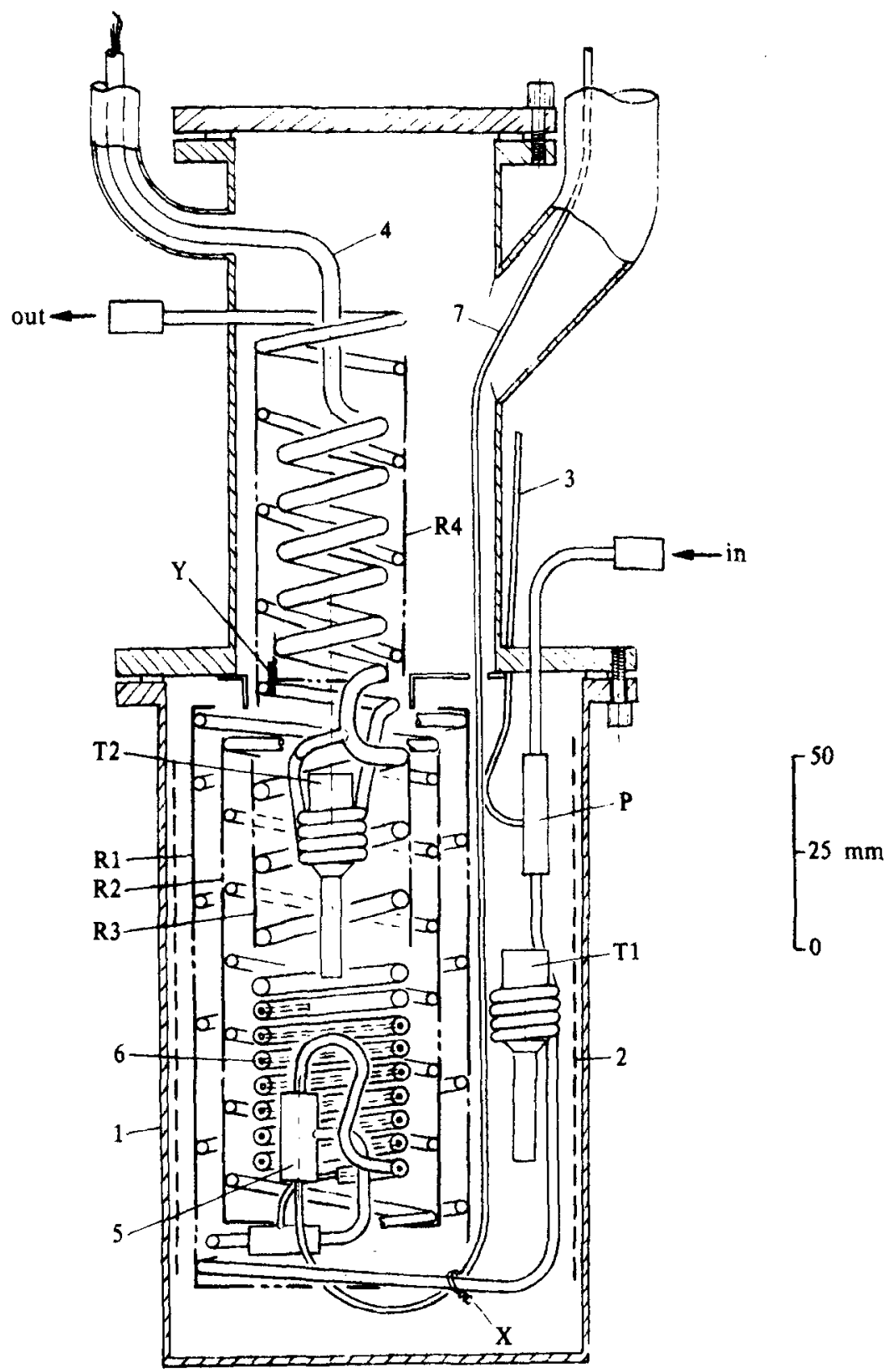

FIGURE 2. Schematic diagram of the calorimeter assembly. 1, Vacuum jacket; 2, guarded radiation shield; 3, calorimeter inlet-pressure tap; 4, calorimeter outlet-pressure tap; 5 , shut-off valve; 6 , calorimeter section; 7 , piano-wire lead tubing; $P$, inlet-pressure tap junction; $R 1$, radiation shield; $R 2$, radiation shield; $R 3$, radiation shield; $R 4$, radiation shield; $T 1$, inlet-thermometer well; $T 2$, outlet-thermometer well ; $X$, thermal contact; $Y$, thermal contact. 
metering pumps, illustrated schematically (P-1A and P-1B) in figure 3, are driven through a gear assembly by a synchronous motor. They are designed to pump liquid at pressures up to $65 \mathrm{MPa}$ at temperatures as low as $77 \mathrm{~K}$. They deliver a volumetric flow constant to within $10^{-5}$. After gravimetric calibration, the accuracy of the flow rate from these pumps is estimated to be \pm 0.05 per cent. The volumetric flow rate of fluid is normally about $0.23 \mathrm{~cm}^{3} \mathrm{~s}^{-1}$, but can be altered by changing the drive gears.

\section{AUXILIARY FACILITIES}

The auxiliary facilities combine the calorimeter and flow-metering pumps into a recycle-flow system in which fluid flow is maintained at a constant rate through the calorimeter at a fixed predetermined pressure.

The scheme for maintaining unidirectionally continuous flow through the calorimeter is illustrated in figure 3 . The pumps act in tandem, one receiving and the other discharging fluid. Four cryogenic solenoid-activated valves V1 to V4 and check valves operate in conjunction with the reversal motion of the pumps to provide unidirectional flow through the calorimeter.

Three sets of calibrated flexible-bellows pressure transducers F-11, F-12, and F-13 are important links for controlling and measuring the pressure. The pressure of the experimental fluid in this essentially constant-volume system is set approximately using bellows F-12 and handpump P-12. The desired pressure is set precisely in a thermostatted tank C-1 of helium and is measured by a Ruska $2400 \mathrm{HL}$ Dead-Weight Gauge through bellows F-13. The pressure of fluid is maintained essentially constant via bellows F-11 by a large helium buffer : tank C-1. This is especially important for smoothing out the slight disturbance in pressure which occurs following reversal of motion of the pumps. The value of the pressure at the calorimeter inlet is determined from the pressure in the tank $\mathrm{C}-1$, the measured pressure difference across $\mathrm{F}-11$, and the pressure drop of the fluid between F-11 and the calorimeter as measured by a transducer (LDPT in figure 3).

The metering pumps along with two sets of bellows $F-11$ and F-12, and the four cryogenic valves $\mathrm{V} 1$ to $\mathrm{V} 4$, are located in the pump bath B-1. For all the measurements reported here the temperature of this bath was $255.37 \mathrm{~K}$ so that ethane was always a liquid within the operating range of pressures $(3$ to $13 \mathrm{MPa}$ ). This liquid ethane is pumped through conditioning coils in the pre-conditioning bath B-2 and in the calorimeter bath B-3, before entering the calorimeter. Both the pre-conditioning and the calorimeter baths are maintained at the desired temperature of the experimental determinations. The post-conditioning bath which is held at $255.37 \mathrm{~K}$ serves to recondition the fluid to the temperature of the pump bath.

The temperature of the calorimeter bath is controlled to $\pm 0.02 \mathrm{~K}$ using a Hallikainen Thermotrol Model 1053 temperature controller. The pump bath temperature is held to $\pm 0.05 \mathrm{~K}$ using a similar Thermotrol Model 1109 temperature controller. A Bayley Model 121 temperature controller is used on the conditioning baths B-2 and B-4. Liquid nitrogen is the coolant for all the baths. 


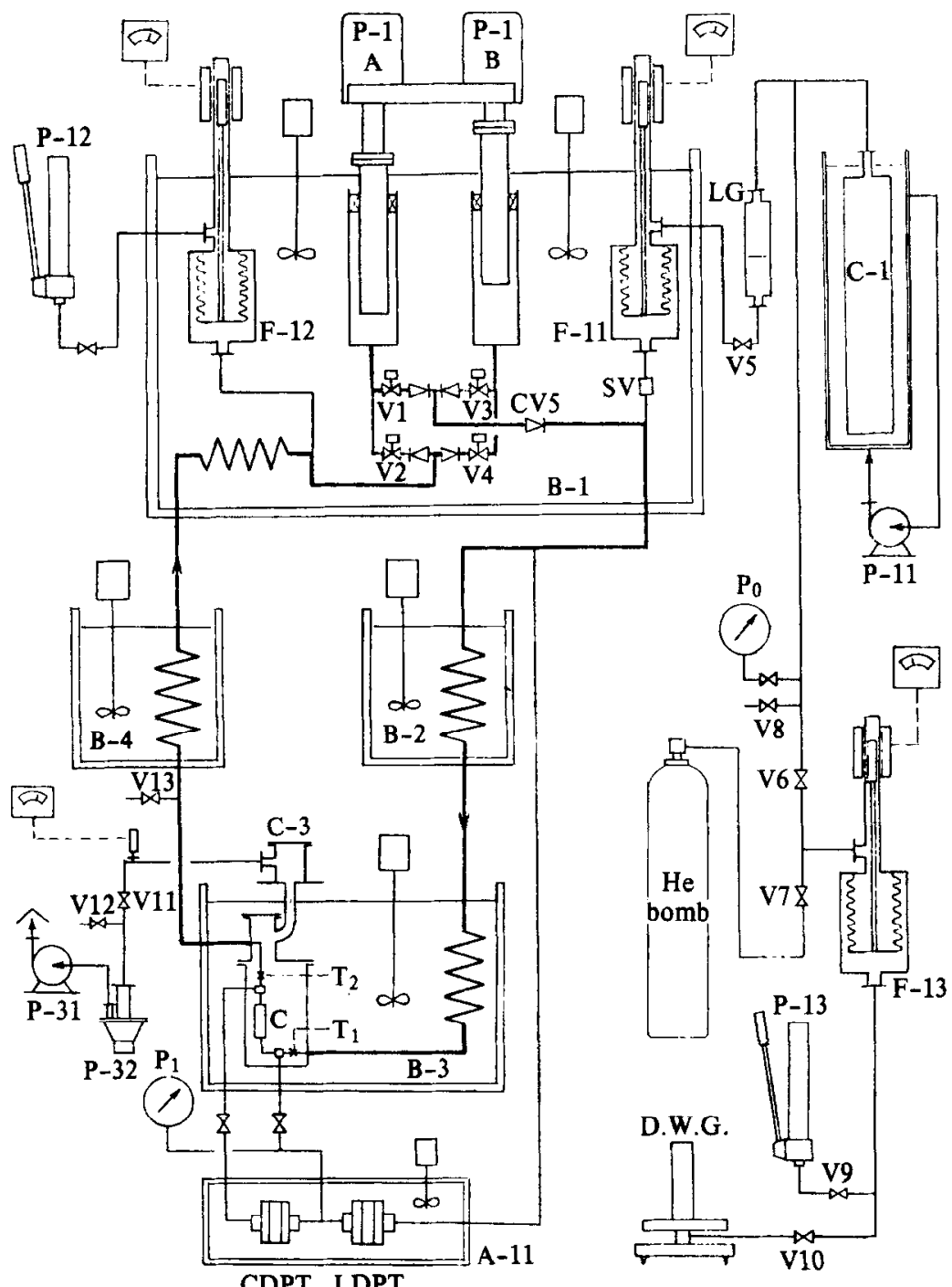

FIGURE 3. Schematic diagram of the recycle-flow calorimetric assembly. P-1A and P-1B, Metering pumps; -1 , solenoid valve; $-K-$, check valve; - $-1-$, shut-off valve ; B-1, pump bath; B-2, pre-conditioning bath; B-3, calorimeter bath; B-4, post-conditioning bath; A-11, air box; F-11, F-12, F13, bellows; LG, level gage; P-12, P-13, oil pumps (manual); P-11, water circulation pump; P-31, vacuum pump: P-32, diffusion pump; $\mathbf{P}_{1}, \mathbf{P}_{\mathrm{o}}$. Heise pressure gages; D.W.G., Ruska dead weight gage; $C$, calorimeter; C-3, calorimeter vacuum pot; CDPT, calorimeter differential pressure transducer; LDPT, line differential pressure transducer; SV, safety valve; T1, inlet thermometer; T2, outlet thermometer; C-1, helium cylinder; V1 to V4, solenoid operated on-off valves; V5 to V13, valves. 


\section{INSTRUMENTATION AND CALIBRATION}

The prime measurements are power, pressures, temperatures, and flowrate. The actual instruments used and their capabilities are listed in table 1.

Power is supplied to the calorimeter by a Kepco power supply and is measured using a standard resistor circuit which is described in detail elsewhere. ${ }^{(2,3)}$ All measurements of d.c. potential are made with a Leeds and Northrup K-5 potentiometer and 9828 null detector.

The temperatures of the fluid at the calorimeter inlet and outlet are measured by inserting the two probes of a Hewlett-Packard Quartz Crystal Thermometer into thermometer wells $\mathrm{T} 1$ and $\mathrm{T} 2$ respectively (figure 2). A redundant measurement of the temperature difference is provided by a 6 -junction thermopile. In this work the temperature of the inlet fluid was assumed to be that measured by the quartz probe at T1. This temperature agreed with the bath temperature measurcd by the platinum resistance thermometer within the combined uncertainties $( \pm 0.02 \mathrm{~K})$ of the two instruments. The calorimeter outlet temperature was calculated from the inlet temperature of the fluid and the temperature difference measured by the thermopile, which agreed $( \pm 0.02 \mathrm{~K})$ with the temperature measured by the quartz probe at $T 2$.

Initially, mass flowrates delivered by the pump were calculated from available volumetric data on ethane. ${ }^{(4)}$ However, gravimetric calibration of the pumps as a

TABLE 1, Calibration and accuracy of key instrumentation used for calorimetric determinations

\begin{tabular}{|c|c|c|c|}
\hline Variable & Instrument & Calibration & $\begin{array}{l}\text { Estimated } \\
\text { accuracy }\end{array}$ \\
\hline Power input & $\begin{array}{l}\text { 1. Kepco PVS 100-IMG d.c. power } \\
\text { supply } \\
\text { 2. Standard resistors } \\
\text { 3. Leeds \& Northrup K-5 Potentio- } \\
\text { meter and } 9828 \text { Null Detector }\end{array}$ & $\begin{array}{l}- \\
\text { N.B.S. }{ }^{a}\end{array}$ & 0.03 per cent \\
\hline $\begin{array}{l}\text { Calorimeter inlet } \\
\text { pressure }\end{array}$ & $\begin{array}{l}\text { 1. Ruska } 2400 \mathrm{HL} \text { oil dead-weight } \\
\text { gauge } \\
\text { 2. F-11 bellows transducer } \\
\text { 3. BLH transducer Type HLD. } \\
\text { Model } 1300\end{array}$ & $\begin{array}{l}\text { N.B.S. } \\
\text { In house } \\
\text { In house }\end{array}$ & $0.0007 \mathrm{MPa}$ \\
\hline Calorimeter pressure drop & 1. Sensotec transducer, Model ZD & In house & \\
\hline $\begin{array}{l}\text { Calorimeter inlet } \\
\text { temperature }\end{array}$ & $\begin{array}{l}\text { 1. Platinum resistance thermo- } \\
\text { meter for calorimeter bath, } \\
\text { Rosemount Model } 162 \mathrm{C} \\
\text { 2. Quartz crystal thermometer } \\
\text { Hewlett-Packard Model } 2801 \mathrm{~A}\end{array}$ & $\begin{array}{l}\text { N.B.S. } \\
\text { Hewlett- } \\
\text { Packard }\end{array}$ & $\begin{array}{l}0.003 \mathrm{~K} \text { in } \\
\text { present tempera- } \\
\text { ture range } \\
\pm 0.02 \mathrm{~K}\end{array}$ \\
\hline $\begin{array}{l}\text { Calorimeter outlet } \\
\text { temperature }\end{array}$ & 1. Quartz crystal thermometer & $\begin{array}{l}\text { Hewlett- } \\
\text { Packard }\end{array}$ & $\pm 0.02 \mathrm{~K}$ \\
\hline $\begin{array}{l}\text { Temperature difference } \\
\text { between calorimeter } \\
\text { inlet and outlet }\end{array}$ & 1. 6-junction thermopile & N.B.S. ${ }^{a}$ & $\pm 0.002 \mathrm{~K}$ \\
\hline Flowrate & Metering pumps & In house & \pm 0.05 per cent \\
\hline
\end{tabular}

- Traceable to N.B.S. See figure 4. 
function of pressure showed our measured densities to be uniformly higher by 0.45 per cent than the reported values. The gravimetric calibrations were used to calculate all mass flowrates because they represent a primary calibration. The calorimetric results reported in the thesis ${ }^{(3)}$ are based on the volumetric determinations and therefore deviate uniformly by about 0.45 per cent from those reported here.

\section{PROCEDURES}

All bath temperatures are fixed at the desired level. The calorimeter valve, 11 in figure 1 , is set for either isobaric or throttling mode. The system pressure is set approximately using pump P-12 and bellows F-12, with valve V-5 closed (see figure 3). The pressure in the helium ballast tank $C-1$ is adjusted to the desired level and valve V-5 is opened, allowing control of the system pressure via bellows F-11. Flow and power are established and the pressure readjusted precisely. This procedure is rapid, and the elapsed time from startup to recording the first point is $90 \mathrm{~min}$ or less.

In the isobaric mode the power supplied to the calorimeter is increased step-wise, and the corresponding step increases of temperature at the calorimeter outlet are noted after steady-state is attained. By reducing these results, the enthalpy difference across the calorimeter corresponding to each outlet temperature measurement is obtained, which may then be interpreted to yield the specific enthalpy of vaporization $\Delta h_{v}$ or isobaric specific heat capacity:(3)

$$
c_{p}=(\partial h / \partial T)_{p} .
$$

In the throttling mode, if the fluid in the calorimeter cools on expansion, electric power is supplied to equalize the calorimeter inlet and outlet temperatures to within about $0.02 \mathrm{~K}$. This type of measurement is repeated at several pressures. The effect of pressure on the isothermal throttling coefficient:

$$
\phi=(\partial h / \partial p)_{T},
$$

may be obtained from these results. ${ }^{(3)}$

An isenthalpic determination can be made if no power is supplied to the calorimeter heater and the Joule-Thomson coefficient $\mu_{\mathrm{JT}}$ may be dircetly obtained $:^{(3)}$

$$
\mu_{\mathrm{JT}}=(\partial T / \partial p)_{h} .
$$

The time required to make any one of these determinations ranges from 15 to $30 \mathrm{~min}$, depending on whether there is high-or low-density fluid in the calorimeter. This time is less than the $40 \mathrm{~min}$ between reversals of the pump at normal flow rates.

\section{Experimental results and their interpretation}

The objectives of the experiments were (a) to obtain better results to test the performance of the equipment, and (b) to better define the thermodynamic properties of ethane in the important critical region. Hence, isobaric and throttling 


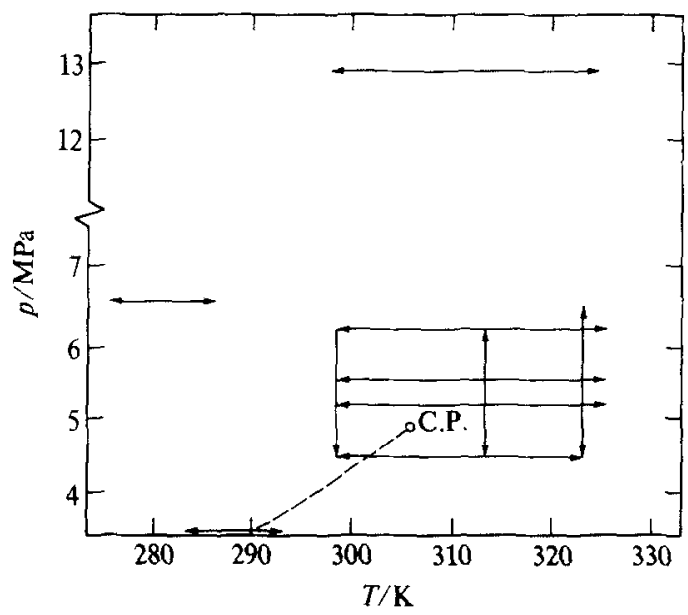

FIGURE 4. Range of calorimetric determinations on cthane.

determinations were made with ethane $\left(99.7\right.$ moles per cent $\mathrm{C}_{2} \mathrm{H}_{6}, 0.3$ moles per cent $\mathrm{C}_{3} \mathrm{H}_{6}$ ) in the vicinity of the critical point, as represented schematically in figure 4 . The enthalpies from these determinations were interpreted to yield values of the enthalpy of vaporization, heat capacities, isothermal throttling coefficients, and JouleThomson coefficients. These values also provided several important checks of thermodynamic consistency.

\section{MEASUREMENTS IN THE ISOBARIC MODE}

Determinations were made which yielded enthalpies of vaporization in the two-phase region and heat capacities near the critical point. The experimental results for all isobaric determinations are listed in table 2 . When operating in this mode there is a small operational pressure difference across the calorimeter ( $\Delta p$ in column 3 ). In order to obtain the true isobaric enthalpy difference $\Delta h$ it is necessary to apply a small correction $\delta \Delta h$ to the ratio of power to flow $P / F$.

The determination of the enthalpy of vaporization at a temperature about $4 \mathrm{~K}$ below the critical temperature is illustrated in figure 5 . Ethane enters the calorimeter as a liquid, and the outlet temperature rises with increasing power input until two phases appear in the calorimeter. The outlet temperature remains relatively constant until all the liquid has vaporized and then rises again with increasing power input. The appearance and disappearance of two phases in the calorimeter is marked by breaks from which the enthalpy of vaporization may be determined.

There is an approximately $0.1 \mathrm{~K}$ rise in temperature across the two-phase region at a fixed pressure (figure 5). This is probably due to the 0.3 moles per cent of $\mathrm{C}_{3} \mathrm{H}_{6}$. The measured enthalpy of vaporization and the temperature of liquid-vapor coexistence at 3.444 and $4.473 \mathrm{MPa}$ are listed in table 3 .

The results of this work are compared in figure 6 with enthalpies of vaporization reported by Furtado ${ }^{(5)}$ and Douslin and Harrison. ${ }^{(6)}$ There is good agreement 
TABLE 2. Experimental isobaric results for cthane

\begin{tabular}{|c|c|c|c|c|c|c|c|c|}
\hline $\begin{array}{l}\text { Run } \\
\text { no, }\end{array}$ & $\frac{p_{\mathrm{i}}}{\mathrm{MPa}}$ & $\frac{\Delta p}{\mathrm{MPa}}$ & $\frac{T_{\mathrm{i}}}{\mathrm{K}}$ & $\frac{T_{\mathrm{o}}}{\mathrm{K}}$ & $\frac{P}{\mathrm{~W}}$ & $\frac{F}{\mathrm{~g} \mathrm{~s}^{-1}}$ & $\frac{\delta \Delta h}{\mathrm{Jg}^{-1}}$ & $\frac{\Delta h}{\mathrm{Jg}^{-1}}$ \\
\hline 1 & 4.4733 & 0 & 298.460 & 300.039 & 1.1966 & 0.10344 & -0.004 & 11.564 \\
\hline 2 & 4.4719 & -0.0003 & 298.446 & 300.987 & 2.1274 & 0.10344 & -0.004 & 20.562 \\
\hline 3 & 4.4733 & -0.0003 & 298.459 & 301.181 & 2.3516 & 0.10344 & -0.004 & 22.730 \\
\hline 4 & 4.4733 & -0.0003 & 298.456 & 301.261 & 2.6001 & 0.10344 & -0.004 & 25.132 \\
\hline 5 & 4.4733 & -0.0001 & 298.455 & 301.298 & 2.9373 & 0.10344 & 0 & 28.396 \\
\hline 6 & 4.4726 & 0.0005 & 298.456 & 301.296 & 3.3241 & 0.10344 & 0 & 32.135 \\
\hline 7 & 4.4726 & 0.0006 & 298.455 & 301.302 & 4.7866 & 0.10344 & 0 & 46.274 \\
\hline 8 & 4.4726 & 0.0006 & 298.457 & 301.327 & 6.5152 & 0.10344 & 0 & 62.984 \\
\hline 9 & 4.4726 & 0.0006 & 298.459 & 301.309 & 7.4791 & 0.10344 & 0 & 72.303 \\
\hline 10 & 4.4726 & 0 & 298.457 & 301.324 & 8.0885 & 0.10344 & 0 & 78.194 \\
\hline 11 & 4.4726 & 0 & 298.457 & 301.330 & 9.3806 & 0.10344 & 0 & 90.685 \\
\hline 12 & 4.4726 & 0 & 298.455 & 301.348 & 10.7683 & 0.10344 & 0 & 104.10 \\
\hline 13 & 4.4733 & 0 & 298.462 & 301.375 & 13.2938 & 0.10344 & 0 & 128.51 \\
\hline 14 & 4.4726 & 0 & 298.445 & 301.874 & 17.5802 & 0.10344 & 0 & 169.95 \\
\hline 15 & 4.4726 & 0.0007 & 298.451 & 303.276 & 19.1420 & 0.10344 & 0 & 185.05 \\
\hline 16 & 4.4726 & 0 & 298.450 & 305.510 & 20.7683 & 0.10344 & 0 & 200.77 \\
\hline 17 & 4.4740 & 0.0004 & 302.506 & 305.021 & 2.1270 & 0.10344 & 0.025 & 20.587 \\
\hline 18 & 4.4740 & 0.0004 & 302.509 & 309.950 & 4.7839 & 0.10344 & 0.021 & 46.269 \\
\hline 19 & 4.4740 & 0.0005 & 302.502 & 319.227 & 8.4992 & 0.10344 & 0.017 & 82.181 \\
\hline 20 & 4.4740 & 0.0005 & 302.510 & 323.836 & 10.0675 & 0.10344 & 0.017 & 97.342 \\
\hline 21 & 4.4740 & -0.0010 & 320.884 & 324.549 & 1.1948 & 0.10002 & -0.038 & 11.908 \\
\hline 22 & 5.1699 & -0.0003 & 298.456 & 302.085 & 2.1276 & 0.10407 & -0.004 & 20.440 \\
\hline 23 & 5.1669 & 0 & 298.462 & 303.750 & 3.3241 & 0.10407 & 0 & 31.942 \\
\hline 24 & 5.1669 & -0.0003 & 298.470 & 305.405 & 4.7858 & 0.10407 & -0.013 & 45.975 \\
\hline 25 & 5.1669 & 0 & 298.470 & 306.733 & 6.5132 & 0.10407 & 0 & 62.587 \\
\hline 26 & 5.1676 & 0 & 298.459 & 307.576 & 8.5048 & 0.10407 & 0 & 81.724 \\
\hline 27 & 5.1676 & 0 & 298.462 & 308.332 & 13.2859 & 0.10407 & 0 & 127.66 \\
\hline 28 & 5.1676 & -0.0001 & 298.468 & 309.267 & 16.0741 & 0.10407 & -0.025 & 154.43 \\
\hline 29 & 5.1676 & 0 & 298.471 & 311.249 & 19.1268 & 0.10407 & 0 & 183.79 \\
\hline 30 & 5.1676 & 0 & 298.469 & 315.383 & 22.4417 & 0.10407 & 0 & 215.64 \\
\hline 31 & 5.1662 & -0.0006 & 313.169 & 318.412 & 3.3198 & 0.10407 & -0.033 & 31.867 \\
\hline 32 & 5.1662 & 0 & 313.178 & 321.364 & 4.7790 & 0.10407 & 0 & 45.925 \\
\hline 33 & 5.1662 & 0 & 313.178 & 325.442 & 6.5034 & 0.10407 & 0 & 62.493 \\
\hline 34 & 5.5144 & -0.0003 & 298.467 & 302.409 & 2.1274 & 0.10439 & -0.004 & 20.375 \\
\hline 35 & 5.5137 & 0 & 298.478 & 306.323 & 4.7854 & 0.10439 & 0 & 45.841 \\
\hline 36 & 5.5144 & -0.0002 & 298.475 & 309.650 & 8.5042 & 0.10439 & -0.008 & 81.456 \\
\hline 37 & 5.5144 & 0 & 298.481 & 310.704 & 10.7617 & 0.10439 & 0 & 103.09 \\
\hline 38 & 5.5144 & 0 & 298.485 & 311.396 & 12.7579 & 0.10439 & 0 & 122.21 \\
\hline 39 & 5.5144 & 0 & 298.485 & 312.725 & 16.0714 & 0.10439 & 0 & 153.95 \\
\hline 40 & 5.5144 & 0 & 298.472 & 314.768 & 19.1240 & 0.10439 & 0 & 183.19 \\
\hline 41 & 5.5158 & -0.0005 & 313.162 & 315.624 & 3.3205 & 0.10439 & -0.059 & 31.749 \\
\hline 42 & 5.5158 & 0 & 313.167 & 319.705 & 6.5060 & 0.10439 & 0 & 62.323 \\
\hline 43 & 5.5158 & 0 & 313.172 & 323.190 & 8.4949 & 0.10439 & 0 & 81.375 \\
\hline 44 & 5.5117 & 0 & 310.171 & 311.341 & 2.7901 & 0.10094 & 0 & 27.643 \\
\hline 45 & 5.5117 & -0.0005 & 310.174 & 312.211 & 5.3126 & 0.10094 & -0.126 & 52.508 \\
\hline 46 & 6.2025 & -0.0004 & 298.487 & 302.899 & 2.1277 & 0.10500 & -0.004 & 20.260 \\
\hline 47 & 6.2025 & 0 & 298.489 & 307.619 & 4.7854 & 0.10500 & 0 & 45.577 \\
\hline 48 & 6.2025 & -0.0003 & 298.488 & 312.614 & 8.5034 & 0.10500 & -0.012 & 80.974 \\
\hline 49 & 6.2025 & 0 & 298.495 & 316.587 & 13.2811 & 0.10500 & 0 & 126.49 \\
\hline 50 & 6.2025 & 0 & 298.496 & 318.507 & 16.0668 & 0.10500 & 0 & 153.02 \\
\hline 51 & 6.2025 & -0.0004 & 298.499 & 320.995 & 19.1282 & 0.10500 & -0.042 & 182.13 \\
\hline 52 & 6.2025 & 0 & 298.497 & 323.290 & 21.2746 & 0.10500 & 0 & 202.62 \\
\hline 53 & 6.1067 & -0.0003 & 297.709 & 303.637 & 2.1276 & 0.10978 & 0 & 19.381 \\
\hline 54 & 6.1067 & -0.0003 & 297.706 & 310.758 & 4.7850 & 0.10978 & 0 & 43.588 \\
\hline
\end{tabular}


TABLE 2-consinued

\begin{tabular}{ccccccccc}
\hline $\begin{array}{c}\text { Run } \\
\text { no. }\end{array}$ & $\begin{array}{c}p_{i} \\
\mathrm{MPa}\end{array}$ & $\frac{\Delta p}{\mathrm{MPa}}$ & $\frac{T_{\mathrm{i}}}{\mathrm{K}}$ & $\frac{T_{\mathrm{o}}}{\mathrm{K}}$ & $\frac{P}{\mathrm{~W}}$ & $\frac{F}{\mathrm{~g} \mathrm{~s}^{-1}}$ & $\frac{\delta \Delta h}{\mathrm{Jg}^{-1}}$ & $\frac{\Delta h}{\mathrm{~J} \mathrm{~g}^{-1}}$ \\
\hline 55 & 6.1067 & -0.0003 & 297.707 & 320.304 & 8.5007 & 0.10978 & 0 & 77.436 \\
56 & 6.1053 & 0 & 297.739 & 325.910 & 10.7747 & 0.10978 & 0 & 98.150 \\
57 & 6.5390 & -0.0003 & 275.215 & 287.229 & 4.1784 & 0.10271 & 0 & 40.682 \\
58 & 6.5376 & -0.0002 & 275.220 & 287.267 & 3.5480 & 0.08691 & 0 & 40.826 \\
59 & 6.5397 & 0 & 275.226 & 287.241 & 1.9439 & 0.04780 & 0 & 40.670 \\
60 & 6.5383 & -0.0004 & 275.215 & 287.244 & 5.1220 & 0.12553 & -0.004 & 40.799 \\
61 & 3.4439 & 0.0002 & 283.178 & 285.328 & 0.9008 & 0.09892 & 0 & 9.107 \\
62 & 3.4439 & 0 & 283.172 & 287.588 & 1.9245 & 0.09892 & 0 & 19.456 \\
63 & 3.4439 & 0 & 283.171 & 288.490 & 2.3505 & 0.09892 & 0 & 23.762 \\
64 & 3.4439 & 0 & 283.191 & 289.019 & 2.5809 & 0.09892 & 0 & 26.092 \\
65 & 3.4446 & 0.0005 & 283.182 & 289.109 & 2.8207 & 0.09892 & 0 & 28.516 \\
66 & 3.4439 & 0 & 283.175 & 288.972 & 3.0707 & 0.09892 & 0 & 31.043 \\
67 & 3.4432 & 0 & 283.176 & 288.968 & 3.3320 & 0.09892 & 0 & 33.685 \\
68 & 3.4446 & 0 & 283.165 & 289.032 & 6.1621 & 0.09892 & 0 & 62.296 \\
69 & 3.4439 & 0 & 283.178 & 289.077 & 12.5983 & 0.09892 & 0 & 127.36 \\
70 & 3.4446 & 0 & 283.165 & 289.133 & 21.8266 & 0.09892 & 0 & 220.65 \\
71 & 3.4446 & 0 & 283.167 & 289.486 & 23.7246 & 0.09892 & 0 & 239.84 \\
72 & 3.4439 & 0 & 283.173 & 289.525 & 24.9294 & 0.09892 & 0 & 252.02 \\
73 & 3.4439 & 0 & 283.171 & 290.407 & 26.4073 & 0.09892 & 0 & 266.96 \\
74 & 3.4439 & 0 & 283.177 & 294.209 & 27.9235 & 0.09892 & 0 & 282.29 \\
75 & 3.4439 & 0.0015 & 283.175 & 296.718 & 28.6987 & 0.09892 & 0 & 290.13 \\
\hline
\end{tabular}

TABLE 3. Specific enthalpies of vaporization $\Delta h_{v}$ at given temperatures and pressures for ethane

\begin{tabular}{ccc}
\hline$p / \mathrm{MPa}$ & $T / \mathrm{K}$ & $\Delta h_{\mathrm{v}} / \mathrm{Jg}^{-1}$ \\
\hline 4.473 & 301.35 & 138 \\
3.444 & 289.05 & 234 \\
\hline
\end{tabular}

between values shown in figure 6 but the enthalpies of vaporization reported here agree more closely with the values of Furtado than those of Douslin and Harrison. The composition of the ethane used by Furtado was very similar to that used in this work with the primary impurity being $\mathrm{C}_{3} \mathrm{H}_{6}(0.3$ to 0.4 mole per cent $)$ whereas Douslin and Harrison's sample contained fewer impurities. Propene is denser than ethane so the enthalpies of vaporization reported here and by Furtado agree more closely and are slightly higher than those given by Douslin and Harrison.

Specific heat capacities $c_{p}$ are obtained by interpreting the results of isobaric determinations in the single-phase region. Typical results at $5.514 \mathrm{MPa}$ are shown in figure 7. Mean values of $c_{p}$, determined both from direct measurements (solid horizontal lines) and by differencing experimental results (dashed horizontal lines), are plotted against temperature. Point values of $c_{p}$ are obtained by a trial-and-error determination of an equal area curve through the mean $c_{p}$ values as indicated by the solid curved line. Values of $c_{p}$ at selected values of temperatures obtained in this manner are presented in table 4. 


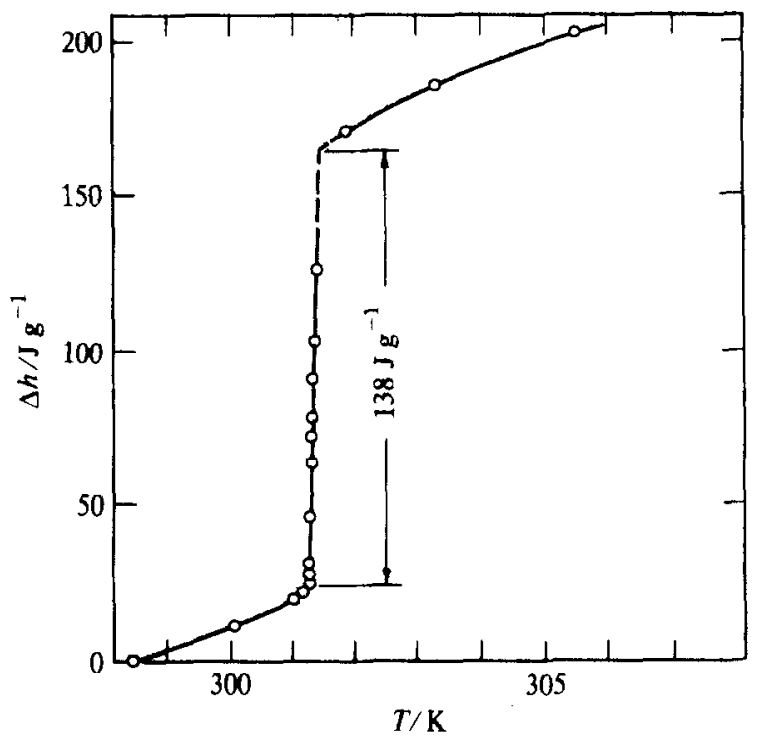

FIGURE 5. Isobaric traverse across two-phase region for the determination of the enthalpy of vaporization of ethane at $4.473 \mathrm{MPa}$.

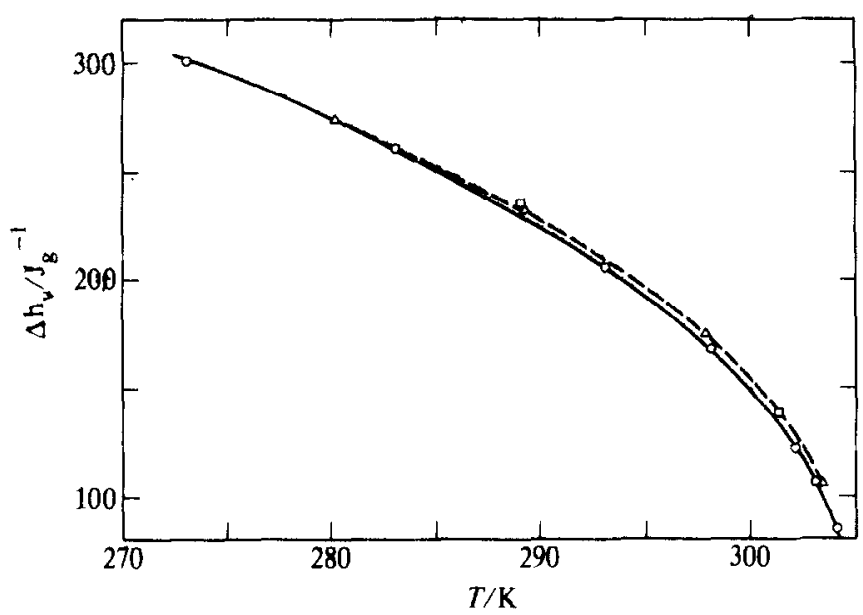

FIGURE 6. Enthalpy of vaporization $\Delta h_{v}$ of ethane. - -, 0 , Douslin and Harrison $;^{(6)} \square$, present results; $-\cdots, \triangle$. Furtado. ${ }^{(5)}$

The variation of heat capacity with temperature at several pressures is shown in figure 8. At a pressure of $5.167 \mathrm{MPa}$, less than $0.3 \mathrm{MPa}$ above the critical point, a sharp peak of magnitude 15 times "normal" values is encountered.

Our heat capacities are compared in figure 8 with values calculated by Goodwin, Roder, and Straty. ${ }^{(7)}$ There is good agreement within their and our combined accuracies. 


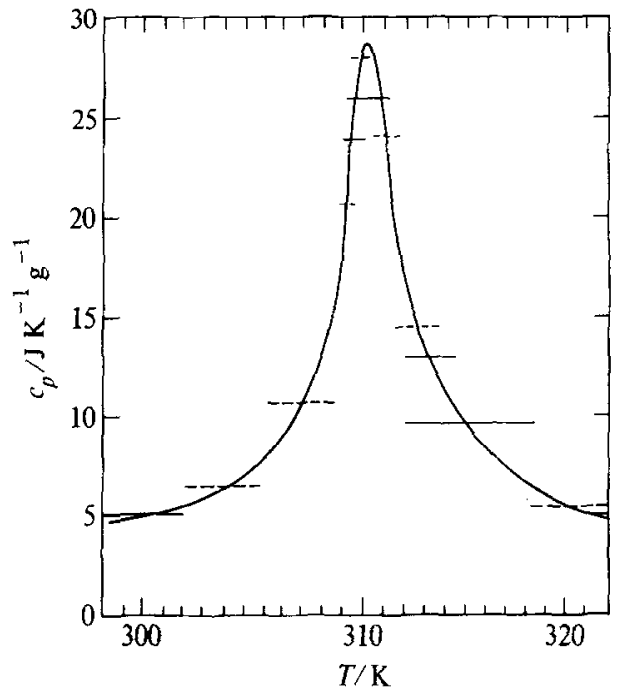

FIGURE 7. Isobaric heat capacity of ethane at $5.514 \mathrm{MPa}$.

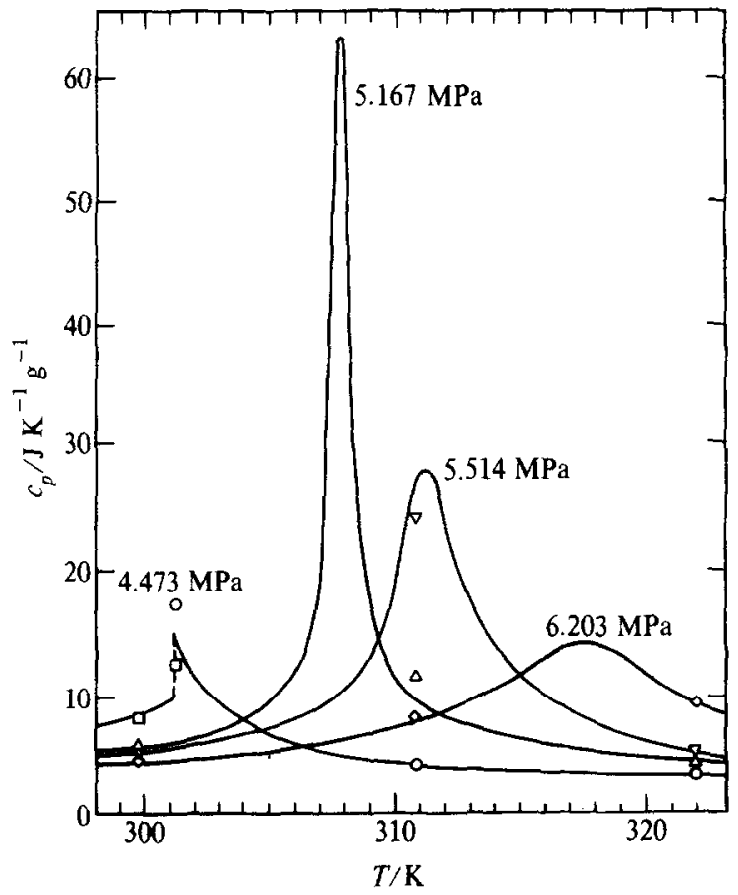

FIGURE 8. Smoothed specific heat capacities of ethane at four pressures shown as solid curves. Comparison with values of Goodwin et al. $.^{(7)} \mathrm{O}, 4.473 \mathrm{MPa}$, liquid phase; $\square, 4.743 \mathrm{MPa}$, vapor phase; $\triangle, 5.167 \mathrm{MPa} ; \nabla, 5.514 \mathrm{MPa} ; \diamond, 6.203 \mathrm{MPa}$. 
TABLE 4. Interpreted isobaric specific heat capacities

\begin{tabular}{|c|c|c|c|c|c|}
\hline$p / \mathrm{MPa}$ : & 4.473 & 5.167 & 5.514 & 6.203 & 13.001 \\
\hline$T / \mathrm{K}$ & \multicolumn{4}{|c|}{$c_{p} / \mathrm{J} \mathrm{K}^{-1} \mathrm{~g}^{-1}$} & \\
\hline 298.15 & 7.24 & 5.06 & 4.77 & 4.39 & 3.230 \\
\hline 303.15 & 9.25 & 7.11 & 5.90 & 4.85 & 3.234 \\
\hline 308.15 & 4.94 & 51.0 & 11.1 & 6.11 & 3.41 \\
\hline 313.15 & 3.97 & 7.70 & 16.3 & 9.71 & 3.51 \\
\hline 318.15 & 3.50 & 5.25 & 7.41 & 13.7 & 3.60 \\
\hline 323.15 & 3.23 & 4.05 & 4.90 & 7.99 & 3.72 \\
\hline \multicolumn{6}{|c|}{ (In the vicinity of the maximum) } \\
\hline & \multicolumn{5}{|c|}{$p=5.167 \mathrm{MPa}$} \\
\hline \multirow{3}{*}{$\begin{array}{l}T / K \\
c_{p} / \mathbf{J ~ K} \mathrm{K}^{-1} \mathrm{~g}^{-1}\end{array}$} & 307.15 & 307.55 & 307.95 & 308.55 & 309.15 \\
\hline & 23.4 & 38.9 & 63.2 & 31.0 & 14.6 \\
\hline & \multicolumn{5}{|c|}{$p=5.514 \mathrm{MPa}$} \\
\hline$T / \mathrm{K}$ & 309.15 & 310.15 & 311.25 & 312.15 & 315.15 \\
\hline \multirow[t]{2}{*}{$c_{p} / J_{K}^{-1} \mathrm{~g}^{-1}$} & 14.6 & 18.8 & 28.9 & 22.8 & 11.3 \\
\hline & \multicolumn{5}{|c|}{$p=6.203 \mathrm{MPa}$} \\
\hline$T / \mathrm{K}$ & 315.15 & 316.55 & 317.45 & 318.15 & 320.15 \\
\hline$c_{p} / J^{-1} \mathrm{~g}^{-1}$ & 12.1 & 13.6 & 14.0 & 13.8 & 11.4 \\
\hline
\end{tabular}

\section{MEASUREMENTS IN THE THROTTLING MODE}

For the present determinations, the pressure drop varied from about $0.07 \mathrm{MPa}$ for measurements in the liquid phase to about $0.2 \mathrm{MPa}$ in the low-density vapor. The enthalpies from these determinations are given in table 5. In the throttling mode, the calorimeter was operated at nearly isothermal conditions. The small operational temperature difference $\Delta T$ across the calorimeter and the required correction $\delta \Delta h$ for non-isothermal conditions are listed in table 5 . This correction is applied to the ratio $P / F$ to obtain the true isothermal enthalpy difference $\Delta h$. Adiabatic measurements of Joule-Thomson coefficients were made by omitting power to the calorimeter.

Isothermal throttling coefficients were determined at several temperatures over a range of pressures as shown in figure 9 . Since the measurements were made with a finite pressure drop across the calorimeter, it was necessary to interpret them to obtain values of $\phi$. This is illustrated for the results at $313.16 \mathrm{~K}$ in figure 9 where mean $\phi$ values obtained from the measured enthalpy differences and pressure drop are plotted as bars. Smoothed values of $\phi$ were obtained by fitting an equal-area curve to the mean $\phi$ values and are plotted as the solid line in figure 9. At this temperature, the isothermal throttling coefficient goes through a maximum, attaining a peak value of $-203 \mathrm{~J} \mathrm{~g}^{-1} \mathrm{MPa}^{-1}$ at $5.612 \mathrm{MPa}$. Smoothed values of $\phi$ as a function of pressure at two other temperatures are also shown in figure 9. Tabulated values obtained from these curves are given in table 6 .

Adiabatic Joule-Thomson measurements were made over a limited range of conditions. The objective of the experiments was to take sufficient points to obtain an 


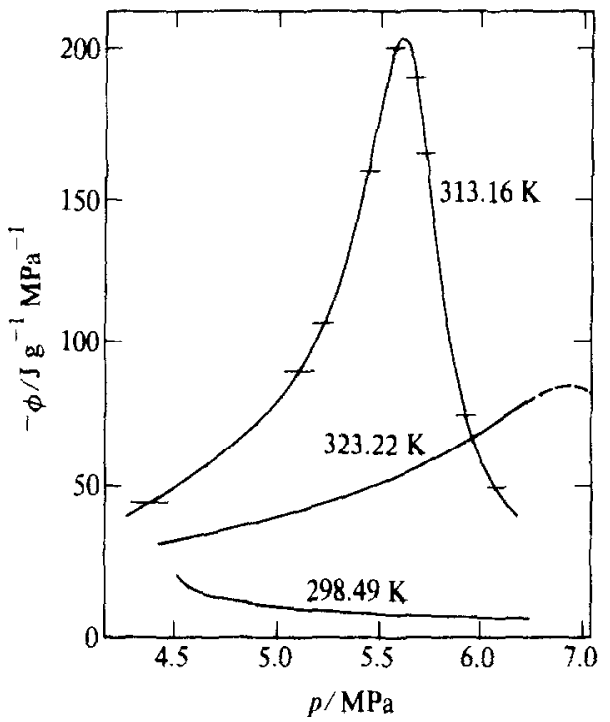

FIGURE 9. Isothermal throttling coefficients $\phi$ of ethane at $298.49,313.16$, and $323.22 \mathrm{~K}$.

TABLE 5. Experimental isothermal results for ethane

\begin{tabular}{|c|c|c|c|c|c|c|c|c|c|}
\hline $\begin{array}{l}\text { Run } \\
\text { no. }\end{array}$ & $\frac{p_{i}}{\mathrm{MPa}}$ & $\frac{\Delta p}{\mathrm{MPa}}$ & $\frac{T_{i}}{K}$ & $\frac{\Delta T}{\mathrm{~K}}$ & $\frac{P}{\mathrm{~W}}$ & $\frac{F}{\mathrm{gs}^{-1}}$ & $\frac{\delta \Delta h}{J_{g}^{-1}}$ & $\frac{\Delta h}{\mathrm{Jg}^{-1}}$ & $\frac{-\phi}{\mathrm{Jg}^{-1} \mathrm{MPa}^{-1}}$ \\
\hline 1 & 4.5843 & 0.0679 & 298.486 & 0.006 & 0.11738 & 0.10344 & -0.0460 & 1.0887 & 16.031 \\
\hline 2 & 5.2469 & 0.0665 & 298.485 & -0.004 & 0.05962 & 0.10408 & 0.0209 & 0.5937 & 8.933 \\
\hline 3 & 5.5241 & 0.0662 & 298.475 & -0.012 & 0.04753 & 0.10436 & 0.0628 & 0.5182 & 7.830 \\
\hline 4 & 6.1825 & 0.0658 & 298.483 & -0.016 & 0.03196 & 0.10497 & 0.0628 & 0.3672 & 5.583 \\
\hline 5 & 4.6195 & 0.1795 & 306.950 & -0.003 & 1.36236 & 0.09997 & 0.013 & 13.639 & 75.972 \\
\hline 6 & 4.8408 & 0.1505 & 306.954 & -0.052 & 2.02738 & 0.10022 & 0.435 & 20.664 & 137.29 \\
\hline 7 & 4.9573 & 0.1309 & 306.958 & 0.029 & 2.94705 & 0.09764 & -0.301 & 29.881 & 228.34 \\
\hline 8 & 5.0532 & 0.0969 & 306.959 & 0.041 & 7.05562 & 0.10047 & -1.046 & 69.178 & 714.12 \\
\hline 9 & 5.1766 & 0.0766 & 306.951 & 0.027 & 0.92722 & 0.10056 & -0.7950 & 8.4260 & 109.99 \\
\hline 10 & 5.3593 & 0.0720 & 306.949 & 0.008 & 0.34053 & 0.10072 & -0.1004 & 3.2805 & 45.530 \\
\hline 11 & 5.6682 & 0.0682 & 306.953 & 0.003 & 0.16097 & 0.10100 & -0.0251 & 1.5686 & 23.004 \\
\hline 12 & 6.1798 & 0.0669 & 306.913 & 0.005 & 0.10297 & 0.10139 & -0.0335 & 0.9822 & 14.685 \\
\hline 13 & 4.4761 & 0.2313 & 313.161 & 0.023 & 1.08633 & 0.10319 & -0.088 & 10.439 & 45.129 \\
\hline 14 & 5.1724 & 0.1645 & 313.163 & 0.019 & 1.41152 & 0.10398 & -0.126 & 13.450 & 81.761 \\
\hline 15 & 5.5158 & 0.1267 & 313.162 & 0.015 & 2.10362 & 0.10428 & -0.221 & 19.951 & 157.52 \\
\hline 16 & 5.7757 & 0.0967 & 313.172 & 0.004 & 1.66442 & 0.10453 & -0.059 & 15.864 & 164.12 \\
\hline 17 & 6.1108 & 0,0828 & 313.173 & 0 & 0.43978 & 0.10483 & 0 & 4.1951 & 50.662 \\
\hline 18 & 5.3062 & 0.1409 & 313.155 & -0.008 & 1.50124 & 0.10061 & 0.059 & $\$ 4.979$ & 106.29 \\
\hline 19 & 5.6447 & 0.1020 & 313.154 & -0.001 & 2.04923 & 0.10094 & 0.017 & 20.317 & 199.24 \\
\hline 20 & 5.7178 & 0.0940 & 313.166 & $-0,002$ & 1.80040 & 0.10100 & 0.029 & 17.855 & 189.99 \\
\hline 21 & 5.9709 & 0.0800 & 313.162 & -0.028 & 0.57518 & 0.10133 & 0.3515 & 6.0276 & 75.365 \\
\hline 22 & 4.6188 & 0.2359 & 323.219 & 0.020 & 0.81646 & 0.09992 & -0.0653 & 8.1061 & 34.367 \\
\hline 23 & 4.7284 & 0.2257 & 323.217 & -0.010 & 0.80298 & 0.10003 & 0.0326 & 8.0602 & 35.717 \\
\hline 24 & 5.1449 & 0.1948 & 323.215 & -0.004 & 0.81611 & 0.10047 & 0.0209 & 8.1437 & 41.796 \\
\hline 25 & 5.5448 & 0.1682 & 323.217 & 0.020 & 0.87004 & 0.10081 & -0.1046 & 8.5263 & 50.682 \\
\hline 26 & 5.9309 & 0.1428 & 323.208 & -0.004 & 0.91130 & 0.10117 & 0.0293 & 9.0372 & 63.290 \\
\hline 27 & 6.2073 & 0.1253 & 323.214 & 0.004 & 0.95349 & 0.10142 & -0.0377 & 9.3640 & 74.746 \\
\hline 28 & 6.3128 & 0.1174 & 323.218 & 0.008 & 0.95349 & 0.10153 & -0.0753 & 9.3161 & 79.155 \\
\hline 29 & 6.7493 & 0.0980 & 323.195 & 0.021 & 0.73557 & 0.10186 & -0.2218 & 6,9996 & 71.392 \\
\hline
\end{tabular}


TABLE 6. Interpreted values of the isothermal throttling coefficient

\begin{tabular}{|c|c|c|c|}
\hline$T / \mathbf{K}:$ & 298.49 & 313.16 & 323.22 \\
\hline$p / \mathrm{MPa}$ & \multicolumn{2}{|c|}{$-\phi / \mathrm{J} \mathrm{g}^{-1} \mathrm{MPa}^{-1}$} & \\
\hline 4.482 & -- & 49.8 & 34.2 \\
\hline 4.826 & 12.0 & 65.5 & 38.5 \\
\hline 5.172 & 9.16 & 98.3 & 44.0 \\
\hline 5.378 & 8.19 & 134 & 48.6 \\
\hline 5.516 & 7.65 & 180 & 52.1 \\
\hline 5.599 & - & 203 & $\cdots$ \\
\hline 5.723 & 6.92 & 166 & 58.4 \\
\hline 5.861 & 6.49 & 96.5 & 63.2 \\
\hline 5.998 & 6.07 & 61.3 & 68.6 \\
\hline 6.205 & 5.52 & 36.4 & 77.2 \\
\hline
\end{tabular}

TABLE 7. Experimental Joule-Thomson coefficients

\begin{tabular}{ccccc}
\hline$p_{\mathrm{i}} / \mathrm{MPa}$ & $-\Delta p / \mathrm{MPa}$ & $T_{\mathrm{i}} / \mathrm{K}$ & $-\Delta T / \mathrm{K}$ & $\mu_{\mathrm{JT}} / \mathrm{K} \mathrm{MPa}^{-1}$ \\
\hline 4.7029 & 0.2293 & 325.785 & 2.385 & 10.40 \\
4.4746 & 0.2433 & 323.429 & 2.578 & 10.50 \\
4.2306 & 0.2610 & 320.912 & 2.848 & 10.91 \\
4.6064 & 0.2484 & 323.176 & 2.644 & 10.64 \\
4.6085 & 0.2525 & 324.865 & 2.652 & 10.50 \\
4.6091 & 0.2556 & 326.163 & 2.657 & 10.40 \\
\hline
\end{tabular}

interpolated value of $\mu_{\mathrm{JT}}$ at $323.22 \mathrm{~K}$ and $4.473 \mathrm{MPa}$ in order to perform the thermodynamic-consistency check described later in this paper.

This check requires that the values of each of the three properties $c_{p}, \phi$, and $\mu_{\mathrm{JT}}$, be obtained at the same conditions, $323.22 \mathrm{~K}$ and $4.473 \mathrm{MPa}$. The procedure for obtaining $\mu_{\mathrm{JT}}$ was more complex than that for $c_{p}$ and $\phi$, which requires only interpretation of basic isobaric and isothermal results, as described earlier. It was necessary to make six isenthalpic determinations at pressures and temperatures about the desired conditions and the value of $\mu_{\mathrm{JT}}$ was obtained by interpolation. The experimental results are listed in table 7 .

\section{Analysis of experimental results}

The experimental results obtained were analysed to check on the performance of the equipment. A test was performed to determine if the heat leak in the calorimeter was less than experimental precision. Also, the isobaric and isothermal results were checked for internal self-consistency using thermodynamics.

\section{CHECK ON THE ASSUMPTION OF ADIABATICITY}

This check is essential since the calorimeter is designed to operate adiabatically, and the interpretation of the results is based on this assumption. Based on a principle 


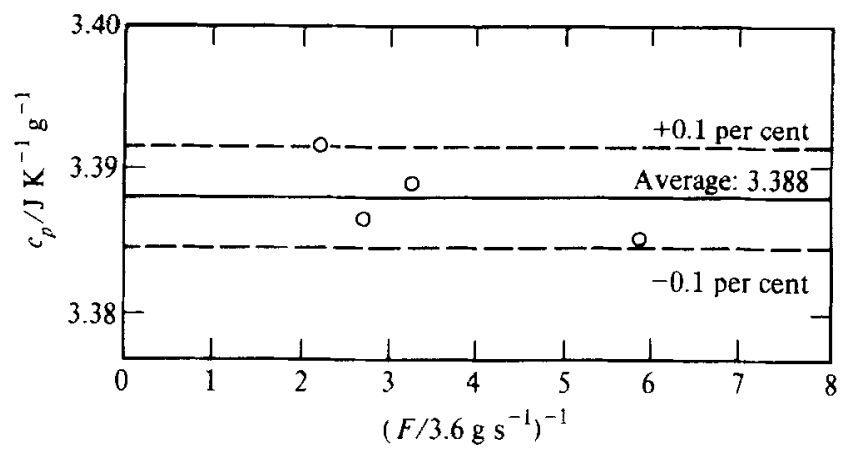

FIGURE 10. Mean heat capacity of ethane as a function of the reciprocal flow rate. Experimental conditions are $p=6.537 \mathrm{MPa}, T_{\mathrm{i}}=275.22 \mathrm{~K}$, and $T_{0}=287.25 \mathrm{~K}$.

suggested by Montgomery and De Vries, ${ }^{(8)}$ mean values of heat capacity were measured at fixed inlet and outlet temperatures and pressures over a range of flow rates to determine if such values are independent of flow rate. Results of measurements at $6.537 \mathrm{MPa}$ (Runs 57 to 60 in table 2) are plotted in figure 10 . The value of the measured mean heat capacity is independent of flow rate within the experimental precision of \pm 0.1 per cent, justifying the assumption that the heat leaks from the calorimeter are negligible.

\section{THERMODYNAMIC-CONSISTENCY CHECKS}

The internal consistency of the results was tested in two ways: (a), by a loop check which sums isobaric and isothermal enthalpy differences around a closed loop in pressure and temperature; and (b), by a check on the mutual consistency of the point values of $\phi, c_{p}$, and $\mu_{\mathrm{TT}}$ at a fixed temperature and pressure.

Loop check. This check is based on the point property behavior of enthalpy where for a closed pressure and temperature loop, the sum of the enthalpy differences for a series of step changes in conditions is equal to zero. In practice, the experimentally determined enthalpy differences for the isobaric and isothermal measurements are summed and the deviation $\delta$ from zero is calculated:

$$
\delta=\sum_{i=1}^{n} \Delta h_{i} / \sum_{i=1}^{n}\left|\Delta h_{i}\right|,
$$

where $\Delta h_{i}$ is the enthalpy change for the $i$ th leg.

This is illustrated in figure 11 for a loop abcdefa which surrounds the critical point and traverses the two phase-region in the leg fa. This loop consists of two isothermal and three isobaric legs shown as solid lines. The dotted lines represent small corrections needed to close the loop.

The two isothermal enthalpy differences ( $a b$ and $c d$ ) were obtained by integrating the appropriate equal-area curves of $\phi$ against $p$ from figure 9 . In contrast, emphasis was placed on the direct experimental measurement of enthalpy in establishing the 


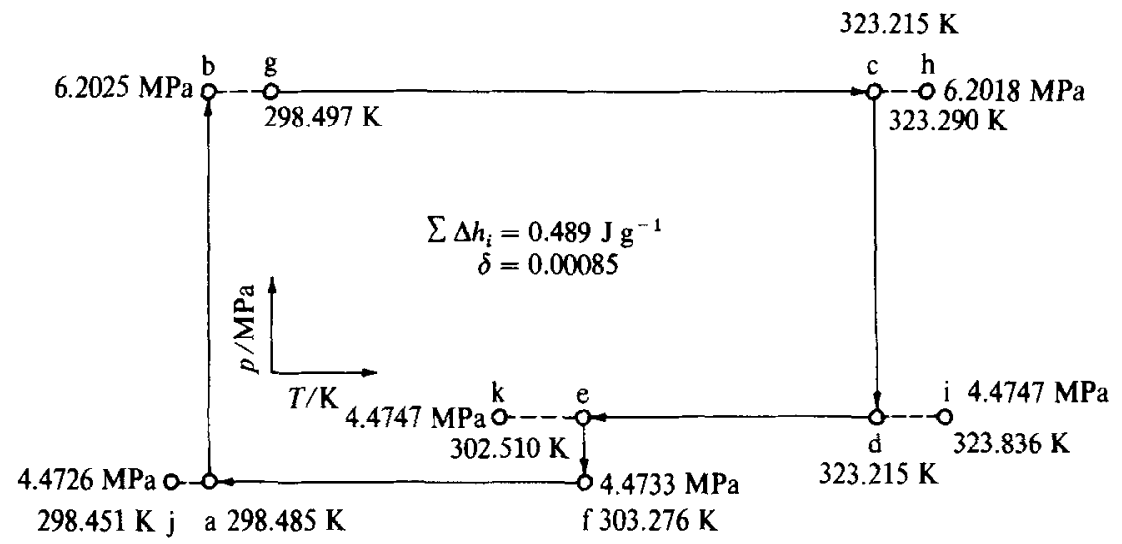

FIGURE 11. Loop for testing the thermodynamic consistency of isobaric and throttling results on ethane (see text).

isobaric legs. For determining the isobaric leg bc, an enthalpy difference of $202.614 \mathrm{~J} \mathrm{~g}^{-1}$ was obtained from run 52 (table 2) between $298.497 \mathrm{~K}$ and $323.29 \mathrm{~K}$ (leg gh). Corrections to $298.485 \mathrm{~K}$ (point b) and $323.215 \mathrm{~K}$ (point C) were calculated using smoothed values of $c_{p}$ at these conditions and their values were $\Delta h_{\mathrm{bg}}=0.054 \mathrm{~J} \mathrm{~g}^{-1}$ and $\Delta h_{\mathrm{ch}}=0.628 \mathrm{~J} \mathrm{~g}^{-1}$.

Results of two separate determinations (runs 15 and 20 of table 2) were used to obtain the enthalpy difference between points $d$ and a. Four small corrections were needed to close the loop. Two of them, $\Delta h_{\mathrm{di}}=2.022 \mathrm{~J} \mathrm{~g}^{-1}$ and $\Delta h_{\mathrm{aj}}=-0.248 \mathrm{~J} \mathrm{~g}{ }^{1}$ were made using smoothed values of $c_{p}$ to obtain correspondence with the temperatures of the isothermal determinations. Two more corrections were needed to join e with $\mathrm{f}$ : (a), the enthalpy difference $\Delta h_{\mathrm{ek}}=7.602 \mathrm{~J} \mathrm{~g}^{-1}$ between $302.510 \mathrm{~K}$ and $303.276 \mathrm{~K}$ was obtained by interpreting isobaric results from runs 13 through 15 ; (b), a value $\phi=-75 \mathrm{~J} \mathrm{~g}^{-1} \mathrm{MPa}^{-1}$ was estimated from isothermal determinations made at other temperatures and was used to calculate the enthalpy change from 4.4747 to $4.4733 \mathrm{MPa}$. The isothermal differences in enthalpy are $\Delta h_{\mathrm{ab}}=-16.259 \mathrm{~J} \mathrm{~g}^{-1}$ and $\Delta h_{\mathrm{cd}}=87.123 \mathrm{~J} \mathrm{~g}^{-1}$.

As indicated in figure 11, when all individual enthalpy differences are added around the closed loop, the result is $0.489 \mathrm{~J} \mathrm{~g}^{-1}$. Expressed as a deviation, according to equation (5), the indicated thermodynamic consistency of the results is 0.085 per cent.

Thermodynamic identity check. The internal consistency of the interpreted values of the derivative properties obtained from isobaric, isothermal, and isenthalpic determinations can be checked by the identity:

$$
\mu_{\mathrm{JT}}=-\phi / c_{p}
$$

At $323.22 \mathrm{~K}$ and $4.473 \mathrm{MPa}$, interpretation of isobaric and isothermal results yielded $c_{p}=3.226 \mathrm{~J} \mathrm{~g}^{-1} \mathrm{~K}^{-1}$ and $\phi=-34.04 \mathrm{~J} \mathrm{~g}^{-1} \mathrm{MPa}^{-1}$. The calculated value of $\mu_{\mathrm{TT}}$ obtained by substituting in equation (6) is $10.55 \mathrm{~K} \mathrm{MPa}^{-1}$. A value for the JouleThomson coefficient of $10.51 \mathrm{~K} \mathrm{MPa}^{-1}$ at the same conditions $(323.22 \mathrm{~K}$ and $4.473 \mathrm{MPa}$ ) was obtained by interpolation of the results from six measurements at temperatures and pressures around the desired values (table 7). Comparison of these 
two values of $\mu_{\mathrm{JT}}$ shows that the thermodynamic identity in equation (6) is satisfied to within 0.4 per cent.

\section{PRECISION AND ACCURACY}

The precision of the isobaric results appears to be about 0.1 per cent and that of the isothermal results about 0.5 per cent. Values of the derivative function estimated from these determinations are subject to errors in interpretation (especially where sharp maxima occur) but are consistent to about 0.4 per cent.

The accuracy of the results reported here is extremely difficult to estimate, especially in the regions close to the critical point where the thermodynamic properties change substantially with small variations in pressure and temperature. Comparisons with other independent experimental determinations would allow a good assessment of the accuracy. In the absence of such comparisons, it appears that the accuracy is about the same as the precision.

Professor D. E. Briggs, Joseph C. Golba, Vijay Khanna, Andre W. Furtado, all of the University of Michigan, Dr Gunter Ernst of the Universität Karlsruhe and Dr B. E. Eakin of P-V-T Inc., Houston, gave helpful information and suggestions. Walter Ruska of Rice University designed and supervised fabrication of precision metering pumps and solenoid-activated low-temperature valves and made helpful suggestions on the design of the pump bath. Edward Rupke and Herbert Senecal, of the ORA Instrument Shop, and Douglas Connell, John Wurster, and Peter Severn of the Chemical Engineering Shop performed valuable services. R. E. Betzig and Kuo Tu, of R \& B Machine Tool Company, Saline, Michigan, designed and supervised fabrication of the driving mechanism for the metering pump, the top plates of the bath, and the electrical control system. Professor J. J. Martin, University of Michigan, made available a Ruska dead-weight gauge. The Dow Corning Corporation, Midland, Michigan, made a gift of a large amount of silicone fluid. Financial support was given principally by the National Science Foundation with valuable supplementary support from the Petroleum Research Fund of the American Chemical Society, the Horace H. Rackham School of Graduate Studies and the College of Engineering (both of the University of Michigan), and the American Oil Foundation. The Asahi Chemical Industry Co. provided T. Miyazaki with a threeyear leave of absence and with financial support during that period.

\section{REFERENCES}

1. Powers, J. E. Advances in Cryogenic Engineering, Volume 18. Timmerhaus, K.: editor. Plenum Press: New York. 1973.

2. Yesavage, V. F.; Mather, A. E.; Katz, D. L.; Powers, J. E. Ind. Eng. Chem. 1967, 59, No. IV, 35.

3. Miyazaki, T. M. Ph.D. Thesis, University of Michigan, Ann Arbor, Michigan. 1973.

4. Pope, G. A. Ph.D. Thesis, Rice University, Houston, Texas. 1971.

5. Furtado, A. W. Ph.D. Thesis, University of Michigan, Ann Arbor, Michigan. 1973.

6. Douslin, D. R.; Harrison, R. H. J. Chem. Thermodynamics 1973, 5, 491.

7. Goodwin, R. D.; Roder, H. M.; Straty, G. C. Thermophysical Properties of Ethane from 90 to $600 \mathrm{~K}$ at Pressures to 700 bar, Technical Note 684. U.S. National Bureau of Standards, Washington, D.C. 1976.

8. Montgomery, J. B.; DeVries, J. J. Am. Chem. Soc. 1942, 64, 2372. 